\title{
Stability Analysis and Modification of Guide Support System of Piston Rod in Labyrinth Reciprocating Compressor
}

\author{
H.N. Tang, S.J. Wang, X.Y. Dong \\ School of Mechanical Engineering \\ Shenyang University of Technology \\ China
}

\begin{abstract}
Based on the characters that the piston rod of labyrinth reciprocating compressors is supported by a guide bearing system in the direction of movement, simplified mechanical model of piston rod is established. To determine the effect of relevant parameters on the vibration and stability of piston rod, modal analysis, harmonic analysis and buckling analysis are performed with ANSYS software. The Analysis result is used for the optimization of the guide support system of piston rod, and good result is obtained.
\end{abstract}

Keywords- reciprocating compressor; labyrinth; piston rod; guide support system; stability analysis

\section{INTRODUCTION}

The cylinder and packing place of labyrinth compressor achieves gas sealing in non-contact way. Guide bearing is supported in the movement direction of piston, and the centering accuracy of piston rod is ensured by the precision fit between crosshead, guide bearing and piston parts. The piston rod, as a core motion artifact of reciprocating compressor, plays a vital role to the movement stability of compressor. The reasonable design of supporting system is very important for reducing vibration and improving the stability of piston rod.

Much research work for reciprocating compressor piston rod can be found, but the study of piston rod in labyrinth compressor is relatively less[1-2]. The domestic studies are mainly focused on the fatigue life, stability and fracture problems of piston rod. For example, piston rod of 6M25-185/31.4A compressor is improved by Lv Wenjuan who has analyzed the reason of fracture, a method of increasing diameter of both connection ends of piston rod is proposed to effectively prevent the plastic yielding deformation with insufficient stiffness [3]. Quantity of works for stability checking on piston rod have been done by Liu Xianbo, who has analyzed bending stability of tail beam jack, passage jack, sprag jack, flashboard jack and pillar piston $\operatorname{rod}[4]$. The analysis result indicates that the stability calculation only considering length of the piston rod without the total span results in piston rod bending in actual application. These research results have reference significance for piston rod stability study of normal reciprocating compressor. Labyrinth reciprocating compressor, compared with common piston compressor, has additional guide bearing for piston rod in the movement direction. It proposes strict limit on vibration amplitude of piston rod. Therefore, in this paper, finite element analysis on piston rod support system of labyrinth reciprocating compressor is performed, and structure optimization is done according to the results of guide bearing to reduce the system vibration and improve the stability of the piston rod.

\section{FORMATION OF FINITE ELEMENT MODEL}

\section{A. Model Analysis}

The actual configuration of piston rod in labyrinth reciprocating compressor is relatively simple[5], and the 3-d model for the guide bearing of piston rod is shown in fig. 1 . For convenient analysis, mobile coordinate system is fixed on the upper end of piston rod. Piston rod is transited through fillets, inclined surface or grooves between the extended end and the shaft, the model is thus appropriately simplified. The interactions between piston, piston rod and crosshead are applied by load.

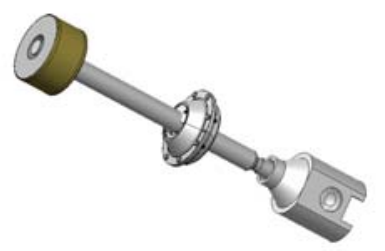

FIGURE I. 3-D MODEL OF GUIDE BEARING OF PISTON ROD.

\section{B. Meshing}

Because of the structural symmetry of compressor piston rod, sweeping division algorithms is used for grid division to ensure the regularity of mesh size and the uniformity of the grid distribution. Then considering the balance of grid density and computational efficiency, overall dimensions is set. Finally the mesh refinement is adopted to handle the transition between shaft and extended end. The number of grid nodes is 158576 and unit number is 32573 .

\section{Application of Load and Constraint}

Piston rod is mainly acted upon by the function of gas pressure and fastening force as fixed load and also affected by reciprocating inertia force and reaction force of guide bearing as cyclic load. For the analysis of reciprocating inertia force, 
the load and constraints on piston rod are simplified. Piston rod is acted under comprehensive axial piston force and constrained by the displacement of guide bearing and crosshead. The supporting effect of guide bearing on piston rod is conversed as equivalent cylindrical restraint on piston rod with free axial displacement and the constraints in other directions. According to the structure of some one type of compressor, the upper end of piston rod is set as $x=0$, and the bar length of middle section is $1290 \mathrm{~mm}$. Providing guide bearing is at the center position, the abscissa value of upper end of guide bearing is $x=750 \mathrm{~mm}$ and width of bearing is Width $=200 \mathrm{~mm}$. The constraint of cross head to piston rod is defined as a fixed constraint, and environment temperature is set as $130^{\circ} \mathrm{C}$, i.e. the average temperature in the cylinder.

\section{INFLUENCE OF LOCATION AND WIDTH OF GUIDE BEARING ON THE STABILITY OF THE PISTON ROD}

\section{A. Modal Analysis of the Piston rod}

Modal analysis, based on the vibration theory, is adopted to obtain the modal parameters of mechanical structure with digital calculation. The BLOCK LANCZOS method inserted in ANSYS software is used to perform the modal analysis for the previous $10^{\text {th }}$ orders modal of piston rod. From the vibration model it can be found that the previous $10^{\text {th }}$ orders of modal vibration shape mainly occurs at the upper position of piston rod and the position between guide bearing and crosshead. The main form is bending vibration, and the previous $10^{\text {th }}$ orders of natural frequency of piston rod are shown in table 1 .

TABLE I. PREVIOUS 10TH-ORDER NATURAL FREQUENCIES OF PISTON ROD

\begin{tabular}{|c|c|c|c|c|c|c|c|c|c|c|}
\hline $\begin{array}{c}\text { Orde } \\
\mathbf{r}\end{array}$ & 1 & 2 & 3 & 4 & 5 & 6 & 7 & 8 & 9 & 10 \\
\hline $\begin{array}{c}\text { Natur } \\
\text { al } \\
\text { frequ } \\
\text { ency } \\
\mathrm{Hz}\end{array}$ & $\begin{array}{c}140.0 \\
8\end{array}$ & $\begin{array}{c}140.1 \\
5\end{array}$ & $\begin{array}{c}715.3 \\
1\end{array}$ & 716.4 & 869.9 & 960.13 & $\begin{array}{c}960.6 \\
8\end{array}$ & $\begin{array}{c}1276 . \\
9\end{array}$ & $\begin{array}{c}1640 . \\
2\end{array}$ & 1644.1 \\
\hline
\end{tabular}

\section{B. Harmonic Analysis of Piston rod}

Harmonic response analysis can be used to determine the stability response of the supporting structure under harmonic changing load with time. The responses of supporting structure under two or more kinds of frequencies will be calculated and the response peak will be found after deformation response curve with frequency is obtained. Because of the clearance between crosshead of piston and guide bearing, and the machining error of parts, the eccentricity of piston will appear in the actual running, and therefore the piston rod is influenced by a radial (transverse) harmonic load with the same frequency as the axial (longitudinal) force of piston. Such load depends on the amount of eccentricity and gas pressure on piston. Here the excitation load is processed as harmonic load, the coordinate value of upper end of guide bearing is set as $x=750 \mathrm{~mm}$, and the bearing width as width $=200 \mathrm{~mm}$. longitudinal and transverse excitation loads with frequencies ranging from 0 to $1000 \mathrm{~Hz}$ are applied on piston rod. With such an example, modal superposition method is adopted to perform harmonic response analysis with response analysis substeps of 50 . The curves of longitudinal and transverse amplitude of piston rod changed with excitation frequency are shown respectively in fig. 2 and fig. 3.

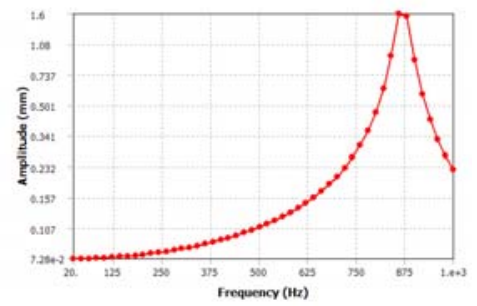

FIGURE II. LONGITUDINAL AMPLITUDE CHANGED WITH EXCITATION FREQUENCY.

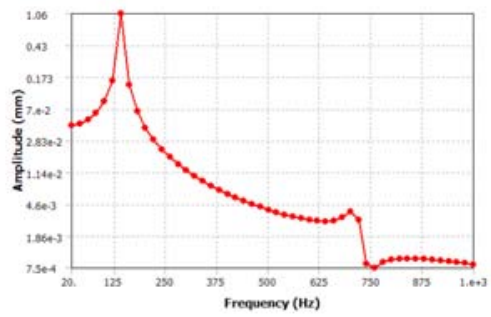

FIGURE III. TRANSVERSE AMPLITUDE CHANGED WITH EXCITATION FREQUENCY.

Within the frequency ranged from 0 to $700 \mathrm{~Hz}$, the transverse amplitude of excitation load increases slowly from $0.0728 \mathrm{~mm}$ with the increase of frequency. Between $700 \mathrm{~Hz}$ and $860 \mathrm{~Hz}$, the longitudinal amplitude increases obviously, and the peak value of $1.59 \mathrm{~mm}$ occurs at $860 \mathrm{~Hz}$. After that point, longitudinal amplitude decreases sharply. In the range of 0 to $140 \mathrm{~Hz}$, transverse amplitude increases sharply with the increase of excitation load frequency, and the peak value of $1.06 \mathrm{~mm}$ appears at the frequency of $140 \mathrm{~Hz}$. Between $140 \mathrm{~Hz}$ and $700 \mathrm{~Hz}$, the transverse amplitude declines rapidly. After the frequency of $700 \mathrm{~Hz}$, transverse amplitude increases occasionally, but the value is so small that it can be ignored.

Referring to table 1, it can be seen that the curve peak of longitudinal amplitude changed with excitation frequency appears near the $4^{\text {th }}$ or $5^{\text {th }}$ order of piston rod natural frequency, while that of the transverse amplitude appears near the first order of natural frequency with apparent resonance effect.

\section{Buckling Simulation Results of Piston rod}

Considering the piston rod of labyrinth reciprocating compressor as a simply middle supported beam structure with one end clamped, therefore the bearing location and width of the guide bearing will inevitably has a great influence on the safety factor. Static analysis is performed for piston rod structure with ANSYS software, and the stress distribution is obtained in fig. 4. Maximum stress value occurs at the fillet transition location between the upper end and the middle of piston rod, and its value of $68.47 \mathrm{MPa}$ is less than yield limit for material of $20 \mathrm{Cr} 13$ selected for piston rod. Based on the structural static analysis, buckling analysis for piston rod 
structure is then performed at the guide bearing location of $750 \mathrm{~mm}$ and for bearing width of $200 \mathrm{~mm}$. The deformation nephogram of piston rod is shown in fig. 5 .

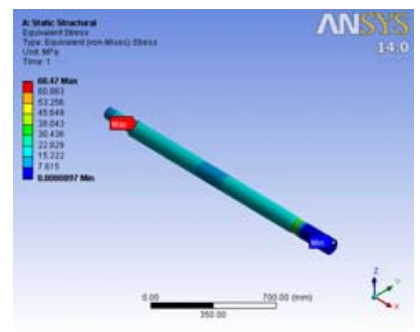

FIGURE IV. STRESS NEPHOGRAM OF PISTON ROD.

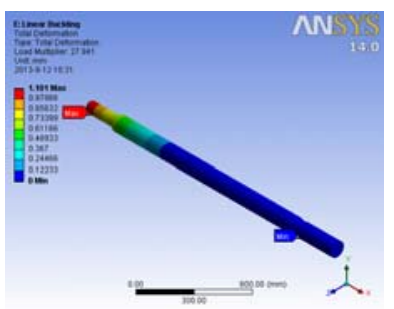

FIGURE V. DEFORMATION NEPHOGRAM OF PISTON ROD.

The stability safety coefficient of compressed rod of piston rod with the value $n_{\mathrm{s}}=27.941$ is obtained from the data in fig. 5. The allowable value for piston rod of vertical labyrinth compressor by Euler formula and Tetmajer formula is selected as $\left[n_{\mathrm{s}}\right] \geq 10 \sim 20[6]$, thus it can be concluded that $n_{\mathrm{s}}>\left[n_{\mathrm{s}}\right]$. The safety coefficient of piston rod complies with the design standards, and therefore the requirement can be satisfied.

\section{STRUCTURAL MODIFICATION OF GUIDE SUPPORTING SYSTEM OF PISTON ROD}

Because the supporting location and width of the guide bearing have great effect on the nature frequency, amplitude and stability of piston rod, it is necessary to make a comprehensive analysis on the influence factors to get the optimum design solution. Parameter analysis function module in ANSYS Workbench is used here, defining the supporting location and width as input parameters. Maximum deformation and maximum stress in static analysis, the previous 10-order of natural frequency in modal analysis, maximum longitudinal and transverse amplitude in harmonic response analysis, safety coefficient in buckling analysis are set as output parameters.

Based on relevant design data of a type of compressor, the bearing location $\mathrm{x}$ is defined in the range from $675 \mathrm{~mm}$ to $825 \mathrm{~mm}$, bearing width is defined from $180 \mathrm{~mm}$ to $220 \mathrm{~mm}$, the number of sample is 100 , and the effects of input parameters on the output parameters is observed through response surface model analysis. The surface of some output parameters changed with the input parameters is shown in fig. 6 and fig. 7.

From fig. 6 and fig. 7 it can be found that, in the scope of samples, the bearing location has a little effect on the strength and stiffness and therefore can to be neglected.
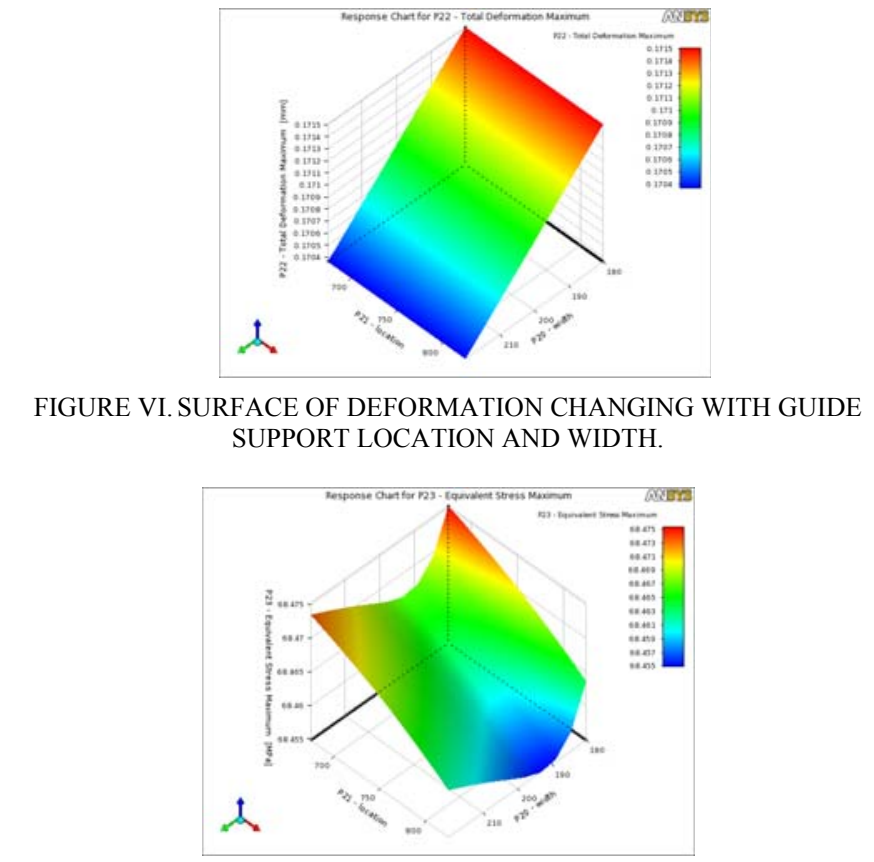

FIGURE VII. SURFACE OF STRESS CHANGING WITH GUIDE SUPPORT LOCATION AND WIDTH.

Fig. 8 shows the first $4^{\text {th }}$ order of natural frequency changed with the parameters of bearing support. The influence of location and width of guide bearing becomes evident gradually with the increase of the order of natural frequency. In the range from $180 \mathrm{~mm}$ to $220 \mathrm{~mm}$ of bearing width, the bearing location plays a main role on the natural frequency of the piston rod, while the effect of bearing width is relatively small. As shown in fig. 9 to fig. 10, the maximum amplitude of longitudinal vibration of piston rod is less than $0.2 \mathrm{~mm}$, while that of transverse vibration lies in the range of $0.286 \mathrm{~mm}$ to $1.245 \mathrm{~mm}$, and the guide bearing location has a greater influence than the width on transverse amplitude.

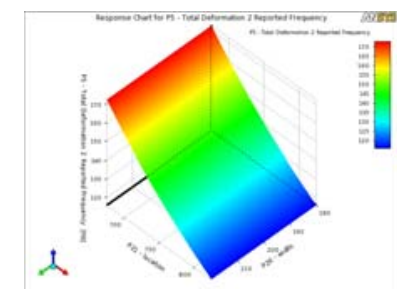

a) The $1^{\text {st }}$ modal natural frequency

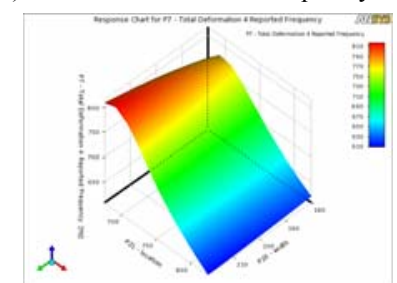

c) The $3^{\text {rd }}$ modal natural frequency b) The $2^{\text {nd }}$ modal natural frequency

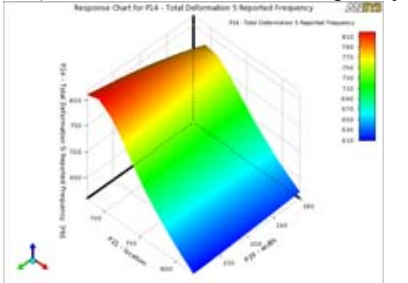

d) The $4^{\text {th }}$ modal natural frequency

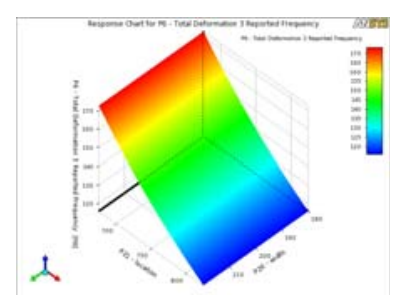

FIGURE VIII. PREVIOUS 4TH ORDER NATURAL FREQUENCIES CHANGED WITH GUIDE SUPPORT LOCATION AND WIDTH. 


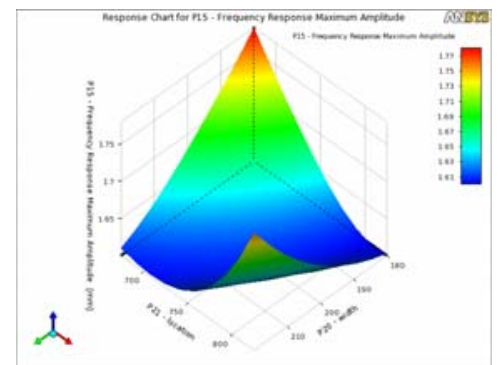

FIGURE IX. SURFACE OF MAXIMUM LONGITUDINAL AMPLITUDE CHANGING WITH LOCATION AND WIDTH OF GUIDE SUPPORT.

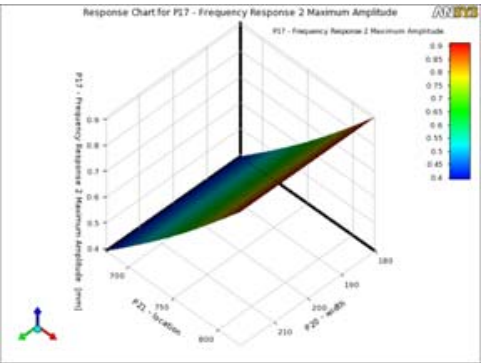

FIGURE X. SURFACE OF MAXIMUM TRANSVERSE AMPLITUDE CHANGING WITH LOCATION AND WIDTH OF GUIDE SUPPORT

From fig. 11 and fig. 12, it can be concluded that maximum longitudinal amplitude of piston rod occurs within the frequency scope of $860 \mathrm{~Hz}$ to $880 \mathrm{~Hz}$ while the maximum transverse amplitude occurs in the range of $140 \mathrm{~Hz} \sim 180 \mathrm{~Hz}$. The longitudinal resonance of piston rod occurs easily near the $4^{\text {th }}$ or $5^{\text {th }}$ order of natural frequency while transverse resonance appears near the $1^{\text {st }}$ or $2^{\text {nd }}$ order of natural frequency.

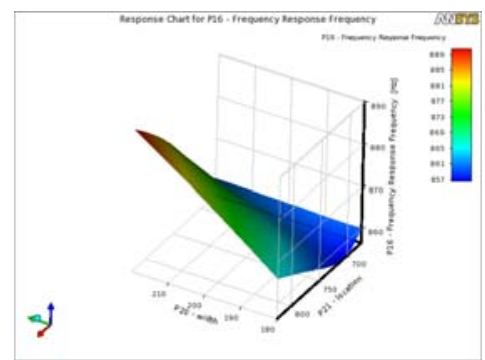

FIGURE XI. SURFACE OF FREQUENCY CORRESPONDING TO MAXIMUM LONGITUDINAL AMPLITUDE.

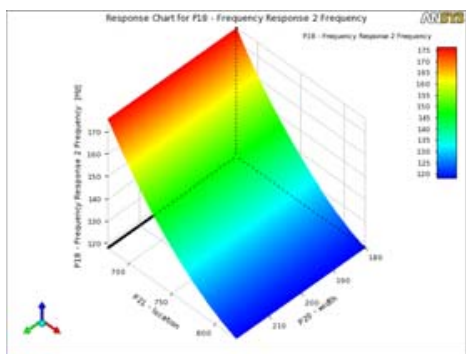

FIGURE XII. SURFACE OF FREQUENCY CORRESPONDING TO MAXIMUM TRANSVERSE AMPLITUDE.
Fig. 13 is the surface of safety coefficient changing with guide bearing location and supporting width. The safety coefficient increases with the coordinate value of supporting location and supporting width. But in practice, the safety coefficient is generally selected greater than 20 , as such it is unnecessary to design the guide bearing specifically considering safety factor if only running requirement is met.

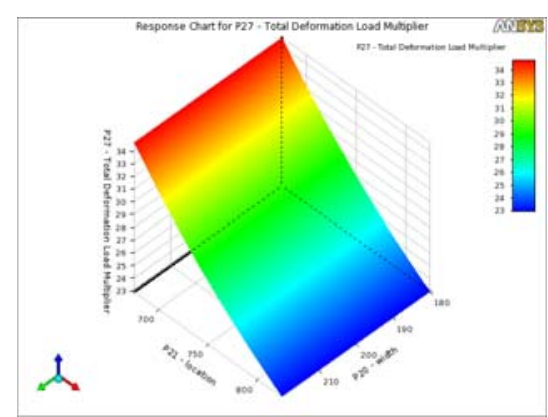

FIGURE XIII. SURFACE OF SAFETY FACTOR CHANGING WITH LOCATION AND WIDTH OF GUIDE SUPPORT.

Based on above parameter analysis result and specific definition of input and output parameters, one or several groups of optimum design points for multiple targets can be obtained with the help of target drive optimization module in Workbench. Here the target value of bearing width is set as "small"; the target value of maximum static deformation is set less than $0.5 \mathrm{~mm}$ with importance level being "high"; the target value of maximum longitudinal amplitude is set as "small" with importance level being "high"; the maximum transverse amplitude is set less than $0.5 \mathrm{~mm}$ with high importance level; Safety factor is set more than 25 with low importance level. Through analysis, two sets of optimal design schemes are achieved and the main parameters are listed in table 2 .

\section{TABLE II. DATA OF THE OPTIMIZING SCHEME.}

\begin{tabular}{|c|c|c|c|c|c|c|c|c|c|}
\hline er & $\begin{array}{c}\text { Sup } \\
\text { p. } \\
\text { widt } \\
\text { h } \\
/ \mathrm{mm}\end{array}$ & $\begin{array}{c}\text { Supp } \\
\cdot \\
\text { posit } \\
\text { ion } \\
/ \mathrm{mm}\end{array}$ & $\begin{array}{l}\text { Max. } \\
\text { longitu } \\
\text { dinal } \\
\text { amplitu } \\
\text { de } \\
/ \mathrm{mm}\end{array}$ & $\begin{array}{c}\text { Correspo } \\
\text { nding } \\
\text { frequenc } \\
\text { y of max } \\
\text { longitudi } \\
\text { nal } \\
\text { amplitud } \\
\mathrm{e} \\
/ \mathrm{Hz}\end{array}$ & $\begin{array}{c}\text { Max. } \\
\text { transv } \\
\text { erse } \\
\text { amplit } \\
\text { ude } \\
/ \mathrm{mm}\end{array}$ & $\begin{array}{c}\text { Correspo } \\
\text { nding } \\
\text { frequenc } \\
\text { y of max. } \\
\text { transvers } \\
\text { e } \\
\text { amplitud } \\
\mathrm{e} \\
/ \mathrm{Hz}\end{array}$ & $\begin{array}{c}\text { Max. } \\
\text { displace } \\
\text { ment in } \\
\text { static } \\
\text { analysis } \\
/ \mathrm{mm}\end{array}$ & $\begin{array}{c}\text { Max. } \\
\text { stres } \\
\mathrm{s} \text { in } \\
\text { static } \\
\text { anal } \\
\text { ysis } \\
\text { /MP } \\
\text { a }\end{array}$ & $\begin{array}{l}\text { fac } \\
\text { or }\end{array}$ \\
\hline 1 & $\begin{array}{c}193 . \\
94\end{array}$ & $\begin{array}{c}709 . \\
35\end{array}$ & 1.661 & 860.136 & 0.498 & 156.202 & 0.171 & $\begin{array}{c}68.4 \\
65\end{array}$ & $\begin{array}{r}31 . \\
48\end{array}$ \\
\hline 2 & $\begin{array}{c}188 . \\
82\end{array}$ & $\begin{array}{c}709 . \\
65\end{array}$ & 1.680 & 858.818 & 0.499 & 156.054 & 0.171 & $\begin{array}{c}68.4 \\
65\end{array}$ & $\begin{array}{c}31 . \\
21\end{array}$ \\
\hline
\end{tabular}

\section{CONCLUSION}

In this paper, with the first-level cylinder in labyrinth reciprocating compressor as research objective, the stability of guide bearing system of piston rod is analyzed and following conclusions can be obtained: 
(1) The location and width of guide bearing have little impact on the strength and stiffness of piston rod. The effect on natural frequency increases gradually with the increase of order. Bearing location plays a leading role on natural frequency.

(2) Location and width of guide bearing have a significant impact on transverse amplitude. Longitudinal resonance easily occurs near the $4^{\text {th }}$ or $5^{\text {th }}$ order of natural frequency of piston rod while transverse resonance often occurs near the $1^{\text {st }}$ or $2^{\text {nd }}$ order of natural frequency.

(3) Based on digital analysis result and specific definition of input and output parameters, an optimum design proposal for multiple targets is achieved with the target drive optimization module in ANSYS software. The effect of input parameter on the output one is determined.

\section{ACKNOWLEDGMENT}

This study was supported by Program for Liaoning Innovative Research Team in University (LT2014003), provided by Education Department of Liaoning Province.

\section{REFERENCE}

[1] Giacomelli Enzo, Falciani Fabil \& Volterrani Guido. Simulation of cylinder valves for reciprocating compressors. Proc. Biennial ASME Conf. American Society of Mechanical Engineers, Torino: Italy, pp.1-10, 2006.

[2] Paul C. Hanlon. Compressor handbook. McGraw-Hill Professional, pp.17.1-17.30, 2001.

[3] Wenjuan Lv. Transformation of the compressor piston rod of 6M25-185/31.4A. Guangdong Chemical Industry, 38 (7), pp. 186-187, 2011.

[4] Xianbo Liu, Meisheng Cui, Chuanwei Zhang. Calculation and analysis on bending stability of roof support hydraulic cylinder piston rod. Coal Mine Machinery, 29 (1), pp. 67-70, 2008.

[5] Yuyan Li, Xiaozhou Dai, Chaohui Chen. Vibration analysis of the piston rod used in labyrinth compressor based on ANSYS. Compressor Technology, 226 (2), pp. $55-58,2011$.

[6] Qinshan Fan. Engineering mechanics (Engineering statics and the material mechanics). China Machine Press: Beijing, pp.78-86, 2009. 